\title{
Investigation on Reproductive Health Knowledge Cognition and Service Demand of University Students-—Based on Three Universities in Huangjiahu University Town
}

\author{
HOU Jia-miao ${ }^{1}$, SHUAI Li-na, ${ }^{1}$ \\ ${ }^{1}$ School of Management, Hubei University of Chinese Medicine, Wuhan 430065, China
}

\begin{abstract}
The paper aims to provide a reference for policy-making on reproductive health services for university students by investigating the recognition degree of reproductive health knowledge and current status of reproductive health service needs of students of three universities in Huangiiahu University Town. The author carries out the questionnaire surveys in the three universities using "wjx", a platform for questionnaire-making, then adopts descriptive analysis and spss analysis to process the data obtained from the questionnaire survey. Sexual behavior among university students is a common phenomenon. However, due to the low cognition degree of reproductive health, they have a strong demand for reproductive health services.
\end{abstract}

\section{Introduction}

With the rapid development of society and the growing popularity of social software, people have more individual and open ideas, also diverse views on sex. The acceptance of premarital sex among university students is increasingly getting higher. In the relatively loose and free environment of university campuses, as university students mature in sexual psychology and reproductive ability, they are constantly facing reproductive health issues and problems including sexual demands arising in love and in the opposite-sex interactions, unintended pregnancy, miscarriage, venereal disease, and AIDS ${ }^{[1]}$. This survey aims to figure out the characteristics of sexual behaviors and current needs of reproductive health services of students in the three universities, find out the shortcomings of existing reproductive health service models, and provide new ideas and perspectives for the transformation from "sex education" that simply imparts physiological structure knowledge to comprehensive and profound "reproductive health education". Meanwhile, the paper is aimed at providing suggestions for policymaking related to reproductive health services for university students, so as to better establish a demandoriented reproductive health service model for university students.

\section{Source and Research Methodology}

\subsection{Survey Objects}

The students of three universities in Huangjiahu university town are chosen as the objects in this research. A total of 369 questionnaires were distributed in this survey, and 347 were effectively received with effective recovery of $94 \%$.

\subsection{Investigation Method}

After studying and analyzing literatures, the questionnaires designed by the author were distributed in three universities to investigate the current situation of reproductive health services accessible to university students, then the data collected went through descriptive statistics and cross-table chi-square test.

\subsection{Statistical Method}

Data were collected on "wjx" platform, processed and analyzed by SPSS25.0. Square test was adopted for the enumeration data, and the statistical significance level is determined as $\alpha=0.05$ (with the confidence interval of $95 \%)$.

\footnotetext{
* Corresponding author: Shuai Li-na, E-mail address:7639571@qq.com
} 


\section{Results and Analysis}

\subsection{Demographic Characteristics of the Objects}

A total of 347 students participated in the survey, including 189 female students and 158 male students, accounting for $54.47 \%$ and $45.53 \%$, respectively; of which 121 students are from Hubei University of Chinese Medicine, 132 from Wuhan University of Science and Technology and 94 from Wuhan Technology and Business University, with the proportion of $34.87 \%, 38.04 \%$ and $27.09 \%$, respectively. As to the distribution of grade, there are 113 freshmen, 124 sophomores, 51 juniors, 45 seniors, and 14 postgraduates, accounting for $32.56 \%, 35.73 \%$, $14.7 \%, 12.97 \%$ and $4.03 \%$ respectively. (See Table 1 )

Table1. Demographic characteristics of the respondents

\begin{tabular}{cccc}
\hline Demographic characteristics & Number & $\begin{array}{c}\text { Constituent } \\
\text { ratio (\%) }\end{array}$ \\
\hline Age & $\leq 17$ & 40 & 11.53 \\
(Year) & $18-24$ & 265 & 76.37 \\
Gender & $\geq 25$ & 42 & 12.1 \\
& Male & 158 & 45.53 \\
Grade & Female & 189 & 54.47 \\
& Freshman & 113 & 32.56 \\
& Sophomore & 124 & 35.73 \\
& Junior & 51 & 14.7 \\
Type of & Senior & 45 & 12.97 \\
University & Postgraduate & 14 & 4.03 \\
& Medical & 121 & 34.87 \\
& Private & 132 & 38.04 \\
& & 94 & 27.09
\end{tabular}

\subsection{Description of Sexual Behavior Characteristics of Respondents}

Among the respondents, 313 students (90.2\%) had penetrative sex; 42 students $(12.1 \%)$ had homo-sexual intercourse; 109 students (31.41\%) often had sexual behaviors in universities (on a monthly basis) and 106 students $(30.55 \%)$ had frequent sexual behaviors; 35 students $(10.1 \%)$ had one-night stand and 216 students ( $75 \%$ ) had dangerous sexual intercourse. (See Table 2 for details)
Frequency of sex since entering the university

Age of the first sexual intercourse

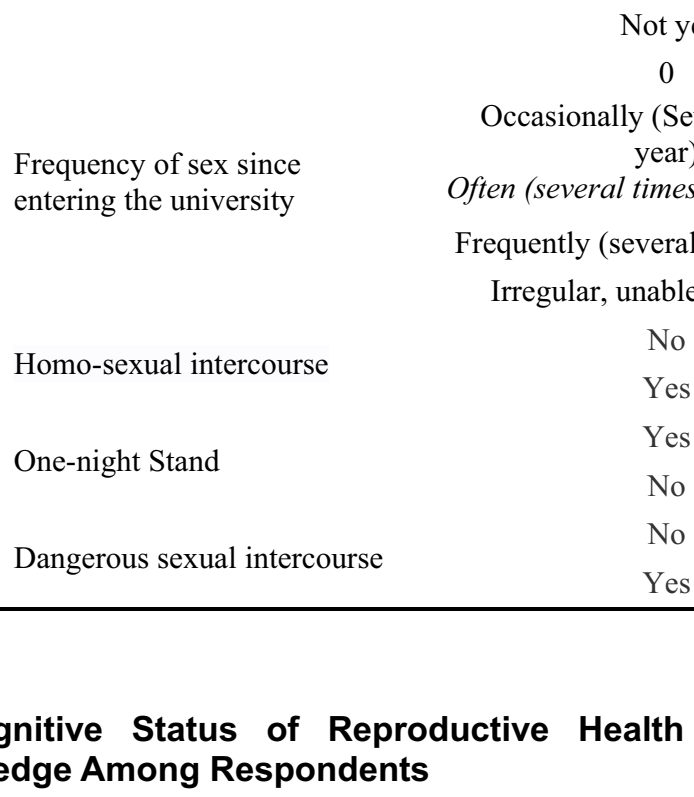

\section{Knowledge Among Respondents}

Among the respondents, 101 students (29\%) had a complete understanding of masturbation-related knowledge; 90 students (25.9\%) knew nothing about preventive measures and the related knowledge of various sexually transmitted diseases, and 122 students (35.1\%) knew only part of the relevant knowledge; 81 students $(23.3 \%)$ did not understand contraceptive knowledge and measures at all and 52 students (14.9\%) almost had no idea of them. (See Table 3 for details). 
Table3. A Survey of Reproductive Health knowledge Among Respondents

\begin{tabular}{|c|c|c|c|}
\hline Item & Type & Number & Proportion $(\%)$ \\
\hline \multirow{3}{*}{ Understanding of masturbation } & $\begin{array}{l}\text { Having some but incomplete } \\
\text { knowledge }\end{array}$ & 117 & 33.6 \\
\hline & $\begin{array}{l}\text { Having comprehensive and } \\
\text { scientific understanding }\end{array}$ & 129 & 37.1 \\
\hline & Knowing nothing & 101 & 29 \\
\hline \multirow{4}{*}{$\begin{array}{l}\text { Being aware of whether all } \\
\text { kinds of sexually transmitted } \\
\text { infections can be prevented }\end{array}$} & $\begin{array}{l}\text { Completely understanding } \\
\text { (including its transmission, } \\
\text { prevention, and treatments ) }\end{array}$ & 83 & 23.9 \\
\hline & Partly understanding & 122 & 35.1 \\
\hline & Knowing nothing & 90 & 25.9 \\
\hline & $\begin{array}{l}\text { Fully aware of the professional } \\
\text { knowledge as medical students }\end{array}$ & 52 & 14.9 \\
\hline \multirow{4}{*}{$\begin{array}{l}\text { Being aware of the most } \\
\text { common channels of } \\
\text { transmission and effective } \\
\text { circumvention of sexually } \\
\text { transmitted diseases including } \\
\text { syphilis, and knowing where to } \\
\text { get HIV testing }\end{array}$} & Completely understanding & 86 & 24.7 \\
\hline & Partly understanding & 142 & 40.8 \\
\hline & Knowing nothing & 70 & 20.1 \\
\hline & $\begin{array}{l}\text { Fully aware of the professional } \\
\text { knowledge as medical students }\end{array}$ & 49 & 14.1 \\
\hline \multirow{5}{*}{$\begin{array}{l}\text { Mastering the knowledge of } \\
\text { contraception and related } \\
\text { measures }\end{array}$} & Completely understanding & 61 & 17.5 \\
\hline & Having a general understanding & 107 & 30.7 \\
\hline & Knowing nothing & 81 & 23.3 \\
\hline & Basically having no idea & 52 & 14.9 \\
\hline & $\begin{array}{l}\text { Fully aware of the professional } \\
\text { knowledge as medical students }\end{array}$ & 46 & 13.2 \\
\hline
\end{tabular}

\subsection{Description of the Reproductive Health Service Needs of the Respondents}

In the question part of investigating the reproductive health needs of university students in the three universities, 100 respondents believed that as long as they took contraceptive measures, they need not worry about unintended pregnancy, accounting for $28.7 \%$ of all respondents, and 72 respondents had unwanted pregnancies themselves or for their partners, accounting for $20.7 \%$; there were $72.4 \%$ of the respondents who had reproductive health needs, but about $60 \%$ of them did not address their reproductive health demands through corresponding services; $51.1 \%$ of them thought it difficult to have access to reproductive health services provided for students in their universities or communities; $75.2 \%$ of the respondents held the view that there were demands for reproductive health service among them at this stage, furthermore, $65.2 \%$ of them argued that they had a strong demand for reproductive health service at present. (See Table 4 for details)

Table4. Survey of Reproductive Health Service Needs of Respondents

\begin{tabular}{|c|c|c|c|}
\hline Item & Type & Number & Proportion ( \% ) \\
\hline \multirow{7}{*}{$\begin{array}{l}\text { Worries caused by unintended } \\
\text { pregnancy }\end{array}$} & $\begin{array}{l}\text { No need to worry as long as } \\
\text { protection measures are taken }\end{array}$ & 100 & 28.7 \\
\hline & You/partner having no & & \\
\hline & unintended pregnancy, but once & 82 & 23.6 \\
\hline & worried for improper measures & & \\
\hline & $\begin{array}{l}\text { You/partner having had } \\
\text { unexpected pregnancy }\end{array}$ & 72 & 20.7 \\
\hline & $\begin{array}{l}\text { No unintended pregnancy } \\
\text { because of correct and proper } \\
\text { protection measures }\end{array}$ & 56 & 16.1 \\
\hline & No penetrative sex & 37 & 10.6 \\
\hline \multirow{4}{*}{$\begin{array}{l}\text { Whether there has been a } \\
\text { demand for reproductive health } \\
\text { services and whether you have } \\
\text { obtained corresponding } \\
\text { services when in need }\end{array}$} & No demand & 96 & 27.6 \\
\hline & $\begin{array}{l}\text { Yes, and receiving } \\
\text { corresponding services }\end{array}$ & 101 & 29 \\
\hline & $\begin{array}{l}\text { Yes, but having no access to } \\
\text { related service }\end{array}$ & 105 & 30.2 \\
\hline & Yes, but solving it by other ways & 45 & 12.9 \\
\hline \multirow{2}{*}{$\begin{array}{l}\text { The difficulty of seeking } \\
\text { reproductive health services for } \\
\text { students in their universities or } \\
\text { the corresponding community }\end{array}$} & $\begin{array}{c}\text { Easy (Not spending too much } \\
\text { time and energy) }\end{array}$ & 50 & 14.4 \\
\hline & $\begin{array}{l}\text { Relatively easy (Taking some } \\
\text { time and energy) }\end{array}$ & 75 & 21.6 \\
\hline
\end{tabular}




\begin{tabular}{lccc}
\hline & Difficult (Taking a lot of time & 178 & 51.1 \\
& and energy) & 44 & 12.6 \\
Is there a demand for & Never followed & 56 & 16.1 \\
reproductive health services & Yo & 91 & 26.1 \\
among university students at & Yes, strongly demanding & 171 & 49.1 \\
the present stage? & Never followed & 29 & 8.3 \\
\hline
\end{tabular}

\section{Discussion and Suggestions}

The author conducted a chi-square test on the data results of the questionnaire in different dimensions, which shows that it is of no statistical significance in terms of the differences in current status of sexual behaviors, reproductive health knowledge and demand for reproductive health service of the university students in the survey, whether from the perspective of different universities, ages and genders.

\subsection{Common Sexual Behaviors Among University Students and Prominent Reproductive Health Problems}

The results show that the phenomenon of penetrative sex is common in students of the three universities. $90.2 \%$ of students have had penetrative sex, and $10.09 \%$ and $75.22 \%$ of them have had one-night stand and dangerous sex, respectively. (See Table 2 for details) In the "2019-2020 National College Student Sexual and Reproductive Health Survey Report", $64.58 \%$ of the respondents accepted premarital sex, $31 \%$ of them had penetrative sex, and $19 \%$ of them actually had one-night stand. It can be seen that among university students, non-marital sex is more and more common. There is no doubt that the concept of sexual behaviors of university students is different from the traditional one linked to marriage.

In 2005, it was abolished that "students who marry without authorization while studying at school and do not go through the dropout procedures shall be treated as dropouts" from Regulations on the Administration of Students in Institutions of Higher Learning [2]. The decision of the Ministry of Education makes it clear that the marriage rights of university students reaching the legally marriageable age are protected by law, and they also have the right to pursue love and meet their sexual needs. On the one hand, their sexual awareness is becoming stronger with the maturing of their sexual psychology. On the other hand, due to a lack of social experience, university students are incompetent to quickly identify all kinds of risks and protect themselves. Coupled with the increasingly open social atmosphere, reproductive health problems among university students have become increasingly prominent, for example, the frequency of unintended pregnancy, induced abortion and AIDS infection is getting much higher ${ }^{[3]}$. Within this context, the existing model of reproductive health education and services for university students needs reconsidering and improving because the reproductive health problems of university students have emerged in all kinds of colleges and universities.

\subsection{The Relatively Low Cognition of Reproductive Health Knowledge Among University Students}

The survey results show that 101 university students knew nothing about masturbation-related knowledge, and those who had little but not comprehensive understanding of masturbation accounted for $29.11 \%$ and $33.72 \%$, respectively; 90 university students had no idea about the common sexually transmitted diseases that are completely curable, and 122 students only understood part of the relevant treatment and preventive measures, accounting for $25.94 \%$ and $35.16 \%$ respectively. According to the question part of contraceptive knowledge, the situation is not optimistic for university students as to understanding the advantages, disadvantages and success rate of various contraceptive methods and other reproductive health knowledge, with $23.34 \%$ of them ignorant of the relevant contraceptive knowledge and $28.82 \%$ of them still believing that the success rate of contraception was $100 \%$, and there was no need to worry about unintended pregnancy as long as protection measures were taken. (See Table 3 for details)

Influenced by traditional historical and cultural factors, most Chinese families are intentionally or unconsciously guiding their children to form an idea that "sex" is an indecent and embarrassing topic, and most families are still afraid of talking about "sex" [4]. In the education concept of traditional families, attention is paid to the education of scientific and cultural knowledge and the cultivation of other professional skills, excluding the education of reproductive health knowledge and relevant measures and methods to maintain reproductive health. What's more, the few reproductive health education activities in colleges and universities do not match the actual needs of students ${ }^{[5]}$. Therefore, university students in the stage of active sexual awareness lack enough knowledge to maintain their reproductive health.

\subsection{Characteristics of Demand for Reproductive Health Services Among University Students}

The survey results show that $64.27 \%$ of the respondents thought that reproductive health services for the prevention and treatment of sexually transmitted diseases are most needed in their college years, and those who had demands for psychological health education in sex and contraceptive reproductive health services accounted for $64.27 \%$ and $54.47 \%$, respectively. From the current 
survey results, as to the reproductive health service demands of university students, they have preference for education on the prevention and treatment of sexually transmitted diseases and contraception, etc., closely linked to the real situation of university students' sexual behaviors. On the one hand, it may be due to the rising number of patients with AIDS and other sexually transmitted diseases and the frequent occurrence of unintended pregnancies among university students. On the other hand, some university students have gradually been aware of reproductive health ${ }^{[6]}$.

\subsection{The Demand for Reproductive Health Services of Students Requiring More Attention from All Parties Concerned}

The results of the questionnaire survey show that $49.38 \%$ of the respondents thought that there was a strong demand for reproductive health services among university students. (See Table 4 for details) Based on the National Survey Report on Sexual and Reproductive Health of University Students from 2019 to $2020,57 \%$ of university students never talked about "sex" with their parents, and for those who did, the frequency was also very low. More than two thirds of the respondents thought that their families tended to be conservative in terms of the attitude towards sex, and more than one third of the respondents suggested that their families had a very traditional attitudes towards sex. $42.02 \%$ of the respondents did not think highly of the sex education in their universities, and $23.50 \%$ of the students were not sure whether the university had sex education or not ${ }^{[7]}$.

Thus, it can be concluded that the reproductive health demand of university students have not been met to a large extent and paid attention to by the social mainstream values. Furthermore, there is a lack of family education on reproductive health. However, the reproductive health education in class is superficial and seriously inconsistent with the actual needs of university students, which fails to teach university students practical methods and skills. To conclude, the reproductive health service for university students does not match their actual needs.

\section{References}

1. Law of the People's Republic of China on the Protection of Minors [M]. National People's Congress. 2020.10.17

2. Ministry of Education of the People's Republic of China. Health Education Guideline for Colleges and Universities [Z].2017.06.14

3. Xu Haiyan, Wang Yun, Zhang Hui, et al. A Survey on the Correlation among Sexual Health Knowledge Attitude and Behavior of University Students [J]. Journal of Jining Medical University, 2019,21(10):78-81

4. Chen Taorong, Tong Jinyuan. Research on Sexual and Reproductive Health Education in Higher Vocational Colleges under the Background of
Healthy China [J]. Journal of Huanggang Polytechnic. 2020:119-121

5. Ji Juan, Li Lianbing, et al. A Survey on Demands of Sex and Reproductive Health Education and Service from University Students in Chongqing [J]. Chongqing Medicine. 2013,12(10):82-83+86

6. Ying Ying, Liu Jianqiao. Development of New Clinical Technology Based on Assisted Reproductive Technology [J]. Journal of Practical Obstetrics and Gynecology, 2020, 36(04):251-253.

7. Zhang Yanli. Survey on Reproductive Health Status and Service Demand of University students in Suzhou University [D].. Suzhou University.2017. 